\title{
¿La jornada intensiva en los centros educativos produce situaciones de desigualdad socioeducativa entre los alumnos?
}

\author{
Do continuous work days at schools produce situations of socio-educational inequal- \\ ity among students?
}

\author{
Joan Tahull Fort \\ e-mail: joantfort@geosoc.udl.cat \\ Universitat de Lleida. España \\ Iolanda Montero Plaza \\ e-mail:ymontero@xtec.cat \\ Departament d'Educació Catalunya. España
}

\section{Resumen}

Este estudio presenta una reflexión, descripción y análisis sobre la implementación de la jornada intensiva en los centros educativos de Cataluña. En los últimos años se ha introducido en casi la totalidad de los centros de secundaria públicos; también en la actualidad hay un plan piloto para valorar su introducción en la escuela primaria. Por el contrario, los centros privados y concertados han mantenido el mismo horario y no han realizado cambios en este sentido. El artículo pretende reflexionar sobre si la jornada intensiva puede producir en algunos casos efectos negativos en los alumnos. Muchos niños/as y adolescentes por las tardes no participan en ninguna actividad extraescolar; estas tienen unos costes elevados y muchas familias no pueden costear los gastos. La situación aboca a determinados colectivos a no realizar actividades fuera del horario escolar y pasan el tiempo en el hogar o con el grupo de iguales principalmente.

Palabras clave: educación; alumno; horario escolar; familia; actividades extraescolares.

\section{Abstract}

This study presents a reflection, description, and analysis of the implementation of continuous work days at educational centers in Catalonia. In the last years, this measure has been introduced in nearly all public secondary schools. Currently, there is also a plan to evaluate the introduction of such measure at primary schools. On the contrary, private and semi-private schools have maintained the same schedule and they have not made any changes in this regard. The article intends to reflect whether or not there might be negative effects on the students. Many of them do not participate in any extracurricular activities after class; as those are expensive and many families cannot afford them. This situation leads to certain groups not doing any activities outside of school hours. Instead, they spend their time mainly at home or with peers in similar circumstances.

Keywords: education; student; school time; family; extracurricular activities.

Recibido / Received: 26-04-2019

Aceptado / Accepted: 17-07-2019

Publicación en linea / Published online: 16-09-2019

Cómo referenciar este artículo / How to reference this article:

Tahull, J., \& Montero, I. (2020). ¿La jornada intensiva en los centros educativos produce situaciones de desigualdad socioeducativa entre los alumnos? Tendencias Pedagógicas, 35, 2020, pp. 74-89. doi: 10.15366/tp2020.35.007 


\section{Introducción}

En los últimos años la educación se encuentra en un estado permanente de cambio. Se cuestionan las metodologías tradicionales ${ }^{1}$ y se apuesta por prácticas más creativas e innovadoras ${ }^{2}$. La educación en las sociedades avanzadas tiene unos retos enormes. Debe formar, educar y socializar para una sociedad futura desconocida, dinámica, cambiante e imprevisible. Terren (1999) considera que la escuela está en un proceso de cambio continuo, teniendo pocos elementos fijos y sólidos. Muchas modificaciones introducidas han sido simples aportaciones que al poco tiempo han dejado de ser significativas para caer en el olvido; aunque algunas han dejado huella en la comunidad educativa (alumnos, profesores y padres), como la introducción de la jornada intensiva ${ }^{3}$. Se ha extendido a la mayoría de los centros públicos de secundaria de Cataluña, también por algunas escuelas de primaria ${ }^{4}$. En la mayoría de estos centros los alumnos empiezan las clases a las 08:00 horas y terminan a las 15:00 horas aproximadamente. Los educados libran por la tarde y pueden disponer del tiempo para realizar múltiples tareas. Algunos realizan actividades paralelas y complementarias (formativas y de ocio), en cambio, otros no realizan ninguna actividad y se quedan en casa o en la calle.

El presente artículo pretende mostrar y reflexionar sobre una realidad social y educativa significativa poco investigada, debido principalmente a su reciente introducción. Nos preguntamos si la jornada intensiva en Cataluña está provocando situaciones de desigualdad por la imposibilidad de acceso de algunos alumnos a determinadas actividades extraescolares. En la investigación no se abordarán todos los elementos implicados en la introducción del horario intensivo, pues está fuera del alcance, solamente se tratará la relación entre el horario intensivo, las dificultades de muchos alumnos para acceder a estas actividades por motivos económicos y la posible no adquisición de determinadas habilidades educativas, deportivas y sociales. También se pretenden mostrar las posibles dificultades de las madres y padres para estar con sus hijos por las tardes y, además, conocer a qué se dedican estos jóvenes que no están en ninguna actividad extraescolar, ¿qué hacen?, ¿con quién están?, ¿cómo ocupan su tiempo?... Se parte de la hipótesis que con la progresiva implantación de la jornada intensiva en los centros públicos de secundaria y primaria se agravan las situaciones de desigualdad social. El hecho de que muchas localidades catalanas no tengan una red de actividades extraescolares de calidad, pública y accesible para todos hace que la situación de desigualdad sea todavía más profunda.

\section{Fundamentación teórica}

Bauman (2003) apunta que la vida social se presenta de forma líquida: estructuras, relaciones y conceptos son inestables. El individuo no tiene elementos fijos de referencia. Destaca la importancia de

\footnotetext{
${ }^{1}$ La escuela tradicional transmitía a los alumnos principalmente conocimientos, virtud y piedad. Los educados deben ser constantemente vigilados ya que su tendencia natural es desviarse hacia el mal. Los maestros deben controlarlos y reconducirlos de cualquier modo hacia modelos adecuados. Al mismo tiempo, si los niños no siguen las conductas adecuadas, cualquier acción puede ser tenida en consideración (Tahull y Montero: 2019).

2 En los últimos años han aparecido diversas metodologías educativas más modernas, avanzadas, flexibles, abiertas... En Cataluña se ha implantado la Escuela Nueva 21, la cual tiene como propósito educativo principal desarrollar competencias para la vida; prácticas de aprendizaje, basadas en el conocimiento existente de cómo las personas aprenden; evaluación competencial y global, contribuye al aprendizaje; y organización autónoma y abierta, capaz de la autorreflexión y la innovación y de actualizarse y formarse.

${ }^{3}$ Tal como explica la noticia en el Periódico, por Caivano, «La jornada intensiva divide a padres y docentes de la ESO».

${ }^{4}$ En la actualidad hay 25 centros de Primaria en Cataluña que realizan el horario intensivo de mañana. En el diario ARA, por Vicens, «Jornada intensiva a l'escola, una prova en qüestió».
} 
la educación en las sociedades avanzadas para mantener, consolidar y equilibrar una sociedad desigual. Molina (2010) considera que en las sociedades democráticas las instituciones deben apostar por la igualdad de oportunidades para todos los infantes. La sociedad y la escuela deben integrar a todos los miembros y no dejar a nadie al margen. Tahull, Molina y Montero (2017) relacionan las dificultades económicas de las familias con los resultados educativos de los hijos. En función del número de miembros de la familia hay más o menos riesgo de caer en la pobreza; la estructura familiar determina los resultados académicos de los hijos. También Tahull (2016) analiza la compleja transición de los adolescentes hacia la vida adulta, al tener estos que integrarse en una sociedad individualista, compleja, caótica, líquida... En las sociedades avanzadas la educación formal (aquella seguida en el centro educativo) no capacita suficientemente a los alumnos y se requiere necesariamente la colaboración de diferentes instituciones para complementar aquellos aspectos que la educación más institucionalizada no consigue consolidar (Moreno: 2016).

González (2016), Carmona, Sánchez y Bekieva (2011), Alonso y Manassero (2007) y Moreno (2006) destacan la relevancia de las actividades fuera del horario escolar para mejorar los resultados académicos. Establecen una relación entre actividades extraescolares y mejor rendimiento educativo. La Convención de las Naciones Unidas sobre los derechos de la infancia establece en su artículo 31 el derecho de los niños a participar en las actividades culturales, artísticas, recreativas y de ocio. Las diferentes administraciones deben crear las oportunidades para que todos los niños puedan participar en igualdad de condiciones. Se debe señalar que las instituciones públicas no están obligadas normativamente a implementar estas actividades, aunque con la extensión de la jornada intensiva no hacerlo deja a muchos niños y menores sin una socialización y formación específica. Torrubia y Batlle (2002) señalan la importancia de educar más allá del horario escolar. En las actividades extraescolares hay más flexibilidad, creatividad y espontaneidad en comparación con las realizadas en la escuela.

Morales (2013) reflexiona sobre la organización de la jornada escolar y considera que la jornada continua tiene algunas consecuencias negativas para los alumnos y sus familias. Se reducen los tiempos de estancia de los alumnos en el centro y este pierde valor como primer lugar de aprendizaje. Para el autor, las actividades extraescolares deberían complementar la formación de los alumnos y en muchos casos no sucede, por falta de actividad adecuada o poca calidad. Destaca también que en algunos casos los monitores no tienen un proyecto educativo definido y claro de la actividad y están mal remunerados. Tinajas (2012) analiza los aspectos positivos y negativos de la jornada continua en primaria y secundaria en diferentes ámbitos, como el rendimiento de los alumnos, los beneficios para la vida familiar... El autor considera que el paso de la jornada partida a la continua perjudica en general el rendimiento del alumno y es un obstáculo para eliminar las desigualdades sociales. Su valoración es especialmente negativa en primaria.

Según el Informe de Save the Children (2012), en referencia a España (también a Cataluña), en los últimos años de crisis económica las administraciones públicas han reducido significativamente la inversión en actividades socioeducativas no lectivas. Las familias deben incrementar cada vez más el gasto en estas actividades, en cambio, la inversión pública se reduce progresivamente. En el informe se alerta sobre la imposibilidad de muchos niños y adolescentes de participar en estas actividades por causas monetarias.

Morales, Galán y Pérez (2017) hacen referencia en su estudio a la visión de los docentes acerca de la jornada continua. Los profesores valoran positivamente el horario principalmente por la posibilidad de formarse y reducir los desplazamientos al centro. En su tesis doctoral, Morales (2015) valora su introducción preguntando mediante entrevistas en profundidad a los miembros de la comunidad educativa (alumnos, profesores, familias, personal de administración y servicios y equipos directivos); con la jornada intensiva los docentes mejoran sus condiciones laborales pero tiene consecuencias negativas para la educación y formación de los alumnos. Desde hace tiempo autores reconocidos de la educación, como Feitó (2007), Sacristán (2008) y Fernández Enguita (2015), entre otros, se posicionan claramente en contra de la jornada continua en los centros educativos de primaria y secundaria.

\section{Metodología}

Para la realización de la investigación se ha utilizado información cuantitativa, principalmente datos del Departament de Salut (2013 y 2016) y el Informe sobre el derecho al ocio educativo del Síndic de Greuges de Cataluña (2014). Se han compilado datos significativos sobre el grado de participación de chicas/os menores de 15 años en actividades extraescolares deportivas y no deportivas en Cataluña, 
también información sobre la evolución de los gastos de las familias en ocio. Esta información permitirá conocer el grado de participación en las diferentes actividades extraescolares y establecer una relación entre diferentes tipologías familiares (en referencia a familias nucleares, monoparentales, número de hijos...). También se introduce información cualitativa ${ }^{5}$ para completar la cuantitativa mediante grupos de discusión, grupos triangulares, entrevistas en profundidad y observación. Esta información permite describir y profundizar en ámbitos más específicos no contemplados en los gráficos. Se han buscado informantes que pudieran presentar una mirada concreta y profunda sobre el objeto de estudio. Se ha realizado la investigación cualitativa en la comunidad autónoma de Cataluña, a partir de reflexiones de profesores, madres y alumnas/os de las cuatro provincias catalanas. La distribución de los participantes ha sido según el criterio: hombre/mujer, escuela pública/concertada, diferentes edades de profesoras/es y alumnas/os. Todos los informantes son anónimos. Se ha accedido a los informantes por ser representativos de los criterios establecidos. Algunos participantes eran conocidos por los autores, a los otros hemos podido conocerlos por allegados o intermediarios, los cuales nos pasaban sus datos y nos poníamos en contacto con ellos.

La subjetividad es un aspecto relevante y significativo en toda investigación social. No se debe interpretar como una limitación o parcialidad, al contrario, es un elemento propio e interesante del tema estudiado. Presenta miradas y reflexiones que no verían la luz de otra manera. En todo caso, no todos los contenidos tienen el mismo valor. Se ha triangulado la información, es decir, se han ponderado, valorado, situado, contrastado y comparado todos los datos (Ander Egg, 2000).

Para la investigación se establecieron dos grupos triangulares y dos grupos de discusión. El primer grupo triangular está integrado por un alumno de primero de bachillerato, una alumna de segundo de bachillerato y una alumna de primero de grado superior de formación profesional. Los tres pertenecen al mismo instituto, en la ciudad de Lleida. El segundo grupo son tres profesores de Barcelona y zonas próximas. Todos trabajan en centros públicos y tienen más de 10 años de experiencia docente. El grupo de discusión está integrado por cinco profesores de un instituto de Tarragona (el equipo directivo del centro: directora, jefe de estudios, secretaria, coordinadora pedagógica y un profesor). Todos son funcionarios (entre 45 y 55 años de edad) con una larga experiencia en diferentes centros públicos.

La siguiente técnica de investigación utilizada fue la entrevista en profundidad. Se buscaron las condiciones más cómodas posibles para que los entrevistados pudieran expresarse con libertad y confianza. Todas se realizaron en sus localidades de residencia y se buscó un lugar adecuado y cómodo. Se ha entrevistado a dos profesoras de Girona y dos de Barcelona, dos alumnas de ESO de Lleida y dos de Bachillerato de Barcelona, y dos madres de Lleida y una de Tarragona. Entre los diferentes perfiles se buscó representación geográfica de Cataluña (las cuatro provincias), escuela pública-concertada, diferentes niveles educativos, hombre-mujer y diferentes edades. La información obtenida permitió tener una visión suficiente, aunque siempre limitada, de las posibilidades de algunas familias para acceder a las actividades extraescolares. Todos los datos recogidos se han ponderado y equilibrado de acuerdo con las constantes y reiteraciones presentadas. La triangulación ha sido un elemento metodológico fundamental en la construcción del relato. La mayoría de la información obtenida no aparece en la investigación, aunque es igualmente importante y ha servido para construir el relato y contrastar la información.

\section{Resultados}

En este apartado se presentan datos cuantitativos y cualitativos sobre las actividades extraescolares de los alumnos catalanes. Muchas instituciones realizan estas actividades aunque hay poco conocimiento de los datos totales. Se pueden encontrar muchas actividades extraescolares pero algunas no tienen la calidad suficiente y no cuentan con un plan educativo definido (Morales: 2013). No hay

${ }^{5}$ Se ha extraído de la tesis doctoral de Tahull (2012). 
datos fiables directos que describan la situación real de todas las actividades realizadas en Cataluña; en cambio, se puede encontrar información más general, la cual permite tener una visión aproximada del grado de participación en las actividades extraescolares. En la Figura $1^{6}$ se presenta el porcentaje de población menor de quince años que ha participado en las últimas semanas en actividades de ocio en Cataluña (2012):

Figura 1.

Porcentaje de población menor de quince años que ha participado en las últimas semanas en actividades de ocio en Cataluña (2012)

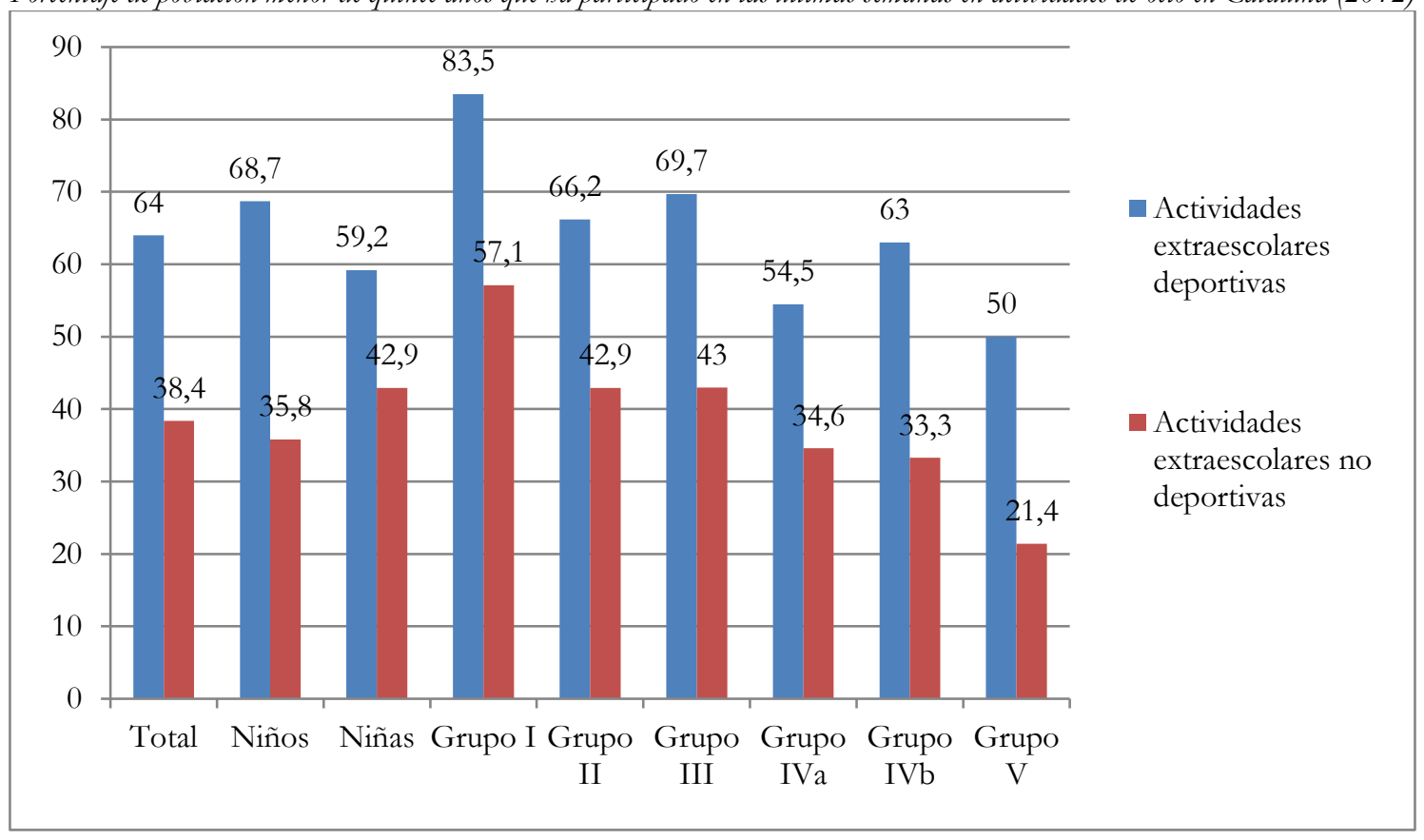

Fuente: elaboración propia a partir de Departament de Salut (2013).

Este gráfico establece una relación entre clase social y participación en las diferentes actividades de ocio (deportivas y no deportivas). Significativamente, los niños y adolescentes participan más en actividades deportivas que no deportivas. En referencia a los niveles de participación, aproximadamente uno de cada tres niños o adolescentes no realiza ninguna actividad extraescolar deportiva y dos de cada tres no participa en ninguna actividad extraescolar no deportiva. Se muestra la relación entre la profesión de los padres y el grado de participación en actividades extraescolares. En el primer grupo, los adultos con mejores condiciones laborales, el 83,5 \% de sus hijos participan en actividades extraescolares deportivas y el 57,1 \% en actividades extraescolares no deportivas. En el segundo grupo, el

\footnotetext{
${ }^{6}$ Los grupos de clase social se han extraído de la Encuesta de Salud de Cataluña (2013) y corresponden a los niveles de ocupación siguiente: Grupo I: directivos de la Administración pública y empresas de diez asalariados o más y profesionales asociados a titulaciones de segundo y tercer ciclo universitario; Grupo II: directivos de empresas de menos de diez asalariados, profesionales asociados a titulaciones de primer ciclo universitario, técnicos y profesionales de soporte, artistas y deportistas; Grupo III: personal administrativo y profesional de soporte a la gestión administrativa y financiera, trabajadores de servicios personales y seguridad, trabajadores por cuenta propia y supervisores de trabajadores manuales; Grupo IVa: trabajadores manuales cualificados; Grupo IVb: trabajadores manuales semicualificados; Grupo V: trabajadores manuales no cualificados.
} 
$66,2 \%$ de sus hijos participan en actividades deportivas y el 42,9\% en actividades no deportivas. En el grupo cinco, integrado exclusivamente por trabajadores manuales no cualificados, el $50 \%$ de sus hijos no participan en actividades deportivas y aproximadamente el $80 \%$ no participan en actividades no deportivas. En el gráfico se observa claramente una relación entre la profesión de los padres y la participación en actividades extraescolares. En aquellas familias cuyos padres tienen mejores condiciones laborales los hijos realizan más actividades extraescolares deportivas y no deportivas; por el contrario, en aquellas con peores condiciones laborales los hijos realizan claramente menos actividades fuera del horario lectivo.

Las posibilidades económicas de las familias tienen relación con las actividades extraescolares realizadas por sus hijos. En un periodo de crisis económica, los gastos de acceso suponen un obstáculo para muchas familias. Estas no pueden asumir los costes y sus hijos no las realizan. No hay datos específicos de los gastos de las familias en las actividades no lectivas. En la Tabla 1 se presenta información de los costes en ocio en general de las familias en Cataluña (2006-2012): 
Tabla 1.

Costes de ocio en general de las familias en Cataluña (2006-2012)

\begin{tabular}{|c|c|c|c|c|}
\hline Gasto & 2006 & 2008 & 2010 & 2012 \\
\hline Ocio, espectáculos y cultura (\% sobre el total) & 6,8 & 7,2 & 6,9 & 5,9 \\
\hline $\begin{array}{l}\text { Servicios deportivos, recreativos y culturales }(\% \text { sobre el } \\
\text { total) }\end{array}$ & 1,5 & 1,6 & 1,5 & 1,4 \\
\hline Ocio, espectáculos y cultura por hogar (en euros) & 2.282 & 2.494 & 2.195 & 1.782 \\
\hline $\begin{array}{l}\text { Servicios deportivos, recreativos y culturales por hogar (en } \\
\text { euros) }\end{array}$ & 498 & 525 & 482 & 417 \\
\hline Ocio, espectáculos y cultura por persona (en euros) & 852 & 950 & 837 & 706 \\
\hline $\begin{array}{l}\text { Servicios deportivos, recreativos y culturales por persona } \\
\text { (en euros) }\end{array}$ & 186 & 200 & 184 & 165 \\
\hline \multicolumn{5}{|l|}{ Riesgo de pobreza } \\
\hline $\begin{array}{l}\text { Riesgo de pobreza de personas en hogares de dos adultos } \\
\text { con dos hijos dependientes }\end{array}$ & 23,3 & 15,8 & 17,8 & 22,5 \\
\hline $\begin{array}{l}\text { Riesgo de pobreza de personas en hogares de dos adultos } \\
\text { con un hijo dependiente o más }\end{array}$ & 21,0 & 16,4 & 21,3 & 24,3 \\
\hline $\begin{array}{l}\text { Riesgo de pobreza de personas en hogares de un adulto con } \\
\text { dos hijos dependientes }\end{array}$ & 41,6 & 48,0 & 46,6 & - \\
\hline
\end{tabular}

Fuente: Instituto de Estadística de Cataluña, a partir de los datos de la Encuesta de presupuestos familiares, base 2006, del INE. Datos del Síndic de Greuges (2014).

En la Tabla 1 se recoge la evolución de los gastos en ocio de las familias y riesgo de pobreza en diferentes años, desde 2006 hasta 2012. La información hace referencia al total familiar, sin concretar las edades, incluye a todos los miembros. En todo caso, hasta 2008 el gasto en ocio, espectáculos y cultura aumentaba. Con la crisis económica este gasto ha ido disminuyendo progresivamente. También se muestran datos sobre el riesgo de pobreza de las familias catalanas. En 2006, el 21,0 \% de las familias con dos adultos y un hijo dependiente o más estaban en riesgo de pobreza. En el año 2012 un $24,3 \%$ de los integrantes de esta tipología familiar estaba en riesgo de pobreza. La tipología familiar de un adulto con dos hijos dependientes tiene las cifras más altas: en 2006 lo estaba el 41,6 \%; en 2008 , el 48,0 \% y en 2010, el 46,6 \%. La gráfica presenta las tipologías familiares con hijos con mayor riesgo de pobreza infantil, aquellas con más dificultades para matricular a sus hijos en actividades extraescolares.

En la Tabla 2 se muestran las actividades de ocio, distinguiendo entre ocio sedentario y activo (de 3 a 14 años):

Tabla 2.

Actividades de ocio sedentario y activo (3-14 años)

\begin{tabular}{lcccccc}
\hline & \multicolumn{2}{c}{ Niños } & & \multicolumn{2}{c}{ Niñas } & \multicolumn{2}{c}{ Total (3.14) } \\
\cline { 2 - 7 } & $\%$ IC 95\% & $\%$ & IC 95\% & $\%$ & IC 95\% \\
\cline { 2 - 7 } $\begin{array}{l}\text { Actividades extraescolares } \\
\text { deportivas }\end{array}$ & 31,2 & $(28,0-34,4)$ & 39,4 & $(36,0-42,8)$ & 35,0 & $(32,7-37,3)$ \\
$\begin{array}{l}\text { Actividades extraescolares de- } \\
\text { portivas }\end{array}$ & 64,7 & $(61,4-68,0)$ & 59,1 & $(55,7-62,5)$ & 62,0 & $(59,6-64,4)$ \\
$\begin{array}{l}\text { Jugar con videojuegos, ordena- } \\
\text { dor o internet }\end{array}$ & 71,6 & $(68,5-74,7)$ & 52,5 & $(49,0-56,0)$ & 62,5 & $(60,1-64,9)$ \\
$\begin{array}{l}\text { Jugar en el parque o en la calle } \\
\text { Mirar la televisión }\end{array}$ & 80,3 & $(77,6-83,0)$ & 73,9 & $(70,8-77,0)$ & 77,2 & $(75,2-79,2)$ \\
\hline
\end{tabular}

Fuente: elaboración propia a partir de Departament de Salut (2016).

El tiempo de ocio fuera del horario escolar, como mirar la televisión, es la actividad más frecuente entre la población de 3 a 14 años. La mayoría de los menores ve la televisión diariamente. Un 35,0 \% de los menores realiza actividades extraescolares no deportivas, más niñas que niños. Por el contrario, en las actividades deportivas participan un $62,0 \%$, en este caso más ellos que ellas. Un porcentaje significativo no realiza ninguna actividad extraescolar. Muchas niñas y niños (un 77,2\%) juegan en el parque o en la calle, un 96,1\% mira la televisión. Para muchos infantes el ocio consiste principalmente en jugar en el parque o en la calle y mirar la televisión. 
En la Tabla 3 se especifica el ocio sedentario de la población de 3 a 14 años por edades y sexo en Cataluña de los años 2014-2015:

Tabla 3.

Ocio sedentario de la población de 3 a 14 años por edades y sexo en Cataluña de los años 2014-2015

\begin{tabular}{|c|c|c|c|c|c|c|c|c|}
\hline \multicolumn{9}{|c|}{ Grupo de edad (años) } \\
\hline & \multicolumn{2}{|r|}{$3-6$} & \multicolumn{2}{|c|}{$7-10$} & \multicolumn{2}{|c|}{$11-14$} & \multicolumn{2}{|c|}{ Total (3-14) } \\
\hline & $\%$ & IC $95 \%$ & $\%$ & IC 95\% & $\%$ & IC $95 \%$ & $\%$ & IC 95\% \\
\hline Niños & 31,4 & $(26,6-36,2)$ & 54,6 & $(48,6-60,6)$ & 60,2 & $(53,5-66,9)$ & 47,4 & $(44,0-50,8)$ \\
\hline Niñas & 23,7 & $(19,1-28,3)$ & 32,1 & $(26,5-37,7)$ & 45,9 & $(38,8-53,0)$ & 33,3 & $(30,0-36,6)$ \\
\hline Total & 27,8 & $(24,4-31,2)$ & 43,6 & $(39,4-47,8)$ & 53,3 & $(48,4-58,2)$ & 40,6 & $(38,2-43,0)$ \\
\hline
\end{tabular}

Fuente: elaboración propia a partir de Departament de Salut (2016).

El 40,6 \% de la población de 3 a 14 años tiene un ocio sedentario (mirar la televisión, jugar a los videojuegos y ordenadores...). El porcentaje es superior en los niños $(47,4 \%)$ que en las niñas $(33,3 \%)$. Es muy importante destacar que con la edad aumenta el sedentarismo. En la Tabla 4 se presenta información sobre el ocio sedentario de la población entre 3 y 14 años, por clase social y sexo y nivel de estudios de la madre en Cataluña (2014-2015)

Tabla 4.

Ocio sedentario de la población entre 3 y 14 años, por clase social y sexo y nivel de estudios de la madre en Cataluña (2014-2015)

\begin{tabular}{|c|c|c|c|c|c|c|c|c|}
\hline & \multicolumn{8}{|c|}{ Clase social según ocupación } \\
\hline & \multicolumn{2}{|c|}{ Clase I } & \multicolumn{2}{|c|}{ Clase II } & \multicolumn{2}{|c|}{ Clase III } & \multicolumn{2}{|c|}{ Total (3-14) } \\
\hline & $\%$ & IC $95 \%$ & $\%$ & IC $95 \%$ & $\%$ & IC $95 \%$ & $\%$ & IC $95 \%$ \\
\hline Niños & 37,6 & $(30,1-45,1)$ & 37,0 & $(29,0-45,0)$ & 53,5 & $(49,2-57,8)$ & 47,4 & $(44,0-50,8)$ \\
\hline Niñas & 20,1 & $(14,1-26,1)$ & 29,1 & $(21,5-36,7)$ & 39,4 & $(35,0-43,8)$ & 33,3 & $(30,0-36,6)$ \\
\hline \multirow[t]{4}{*}{ Total } & 28,7 & $(23,8-33,6)$ & 33,1 & $(27,5-38,7)$ & 46,9 & $(43,8-50,0)$ & 40,6 & $(38,2-43,0)$ \\
\hline & \multicolumn{8}{|c|}{ Nivel de estudios de la madre } \\
\hline & \multicolumn{2}{|c|}{ Universitarios } & \multicolumn{2}{|c|}{ Secundarios } & \multicolumn{2}{|c|}{$\begin{array}{c}\text { Primarios y sin estu- } \\
\text { dios }\end{array}$} & \multicolumn{2}{|c|}{ Total (3-14) } \\
\hline & $\%$ & IC 95\% & $\%$ & IC 95\% & $\%$ & IC $95 \%$ & $\%$ & IC $95 \%$ \\
\hline Niños & 38,0 & $(30,5-45,5)$ & 50,1 & $(41,8-58,4)$ & 56,0 & $(51,7-60,3)$ & 47,4 & $(44,0-50,8)$ \\
\hline Niñas & 21,4 & $(15,3-27,5)$ & 38,4 & $(30,3-46,5)$ & 37,7 & $(33,3-42,1)$ & 33,3 & $(30,0-36,6)$ \\
\hline Total & 30,0 & $(25,1-34,9)$ & 44,6 & $(38,7-50,5)$ & 46,8 & $(43,7-49,9)$ & 40,6 & $(38,2-43,0)$ \\
\hline
\end{tabular}

Fuente: elaboración propia a partir de Departament de Salut (2016).

El ocio sedentario de la población de entre 3 y 14 años presenta mayor incidencia en las clases más desfavorecidas. El porcentaje de niñas/os de la clase I que realiza un ocio sedentario es del 28,7 \%, en la clase II es del 33,1 \% y en la III es del 46,9\%. En referencia al nivel de estudios de la madre, hay una relación entre los estudios de la madre y el tipo de ocio de sus hijos. Solamente el 30,0 \% de los hijos de madres con titulaciones universitarias realizan ocio sedentario, en contraste con el 44,6\% de los hijos de las que tienen estudios de secundaria y el $46,8 \%$ de los hijos de las que carecen de estudios o tienen estudios mínimos.

González (2016) destaca que las actividades extraescolares propician impactos en los procesos de aprendizaje de los alumnos. Participar en determinadas actividades extraescolares equivale a dos meses sobre el progreso académico medio de los alumnos en un curso escolar y dos meses y medio en

\footnotetext{
${ }^{7}$ La clase I hace referencia a directores, gerentes y profesionales universitarios; la clase II corresponde a ocupaciones intermedias y trabajadores por cuenta propia; y la clase III se refiere a los trabajadores manuales.
} 
los alumnos más vulnerables. Carmona, Sánchez y Bekieva (2011) destacan que aquellos alumnos que realizaron determinadas actividades extraescolares académicas como idiomas e informática obtuvieron mejores resultados en todas las materias curriculares. Vázquez y Manassero (2007) relacionan las actividades extraescolares con mejores resultados educativos en ciencia y tecnología.

Resultan pertinentes las aportaciones de los entrevistados para completar y contextualizar la información cuantitativa. Se empezará con las reflexiones de las madres y las profesoras y se finalizará con los/as alumnos/as. Las tablas numéricas ofrecen datos generales sin las experiencias vitales y específicas de los sujetos. En todas las aportaciones surge la reflexión sobre la familia, los cambios acaecidos en los últimos años y el papel de las madres y los padres sobre sus hijos. Tal como explica Elzo (2008), las familias han seguido un proceso de transformación profunda. Señala principalmente la incorporación masiva de las mujeres, madres, al mercado laboral, dejando en muchos casos el hogar sin una figura clara adulta de referencia. En muchas familias los padres no han entrado en las tareas del hogar y se produce un vacío.

Cristina, madre de una hija de 13 años, trabaja en una tienda en Lleida ciudad. La familia vive una situación social y económica difícil. Explica la relación compleja con su hija y la angustia por el futuro:

«Es una niña rebelde, cada día lo es más. A mí no me hace caso. Cada mañana cuando me levanto no quiere ir a la escuela. Me chilla y me dice de todo. Entonces me pongo nerviosa y poco a poco me pongo histérica. Hace unos años cogí una depresión.

Pregunta: ¿Por qué?

Respuesta: La niña me superaba. Se porta muy mal. Yo pienso que lo hace para hacerme enfadar. Le gusta verme fuera de mis papeles. Creo que es lo que le gusta. ¡No sé qué pensar! Antes la podía dominar, pero ahora ya no puedo, me supera, no puedo...

Pregunta: ¿Cómo le va en el instituto?

Respuesta: Mal. Muy mal. Tiene notas muy bajas y no sé qué hacer con ella. Me dicen que me tengo que poner con ella. Ayudarla con los deberes y estas cosas. Dicen que tengo que estar a su lado, pero no puedo. Ahora estoy trabajando en una tienda y llego pasadas las 8 de la tarde. Mi marido ha estado un tiempo en el paro, a él le hace un poco más de caso, pero a mi nada, me vapulea. Mi marido es camionero y ha estado unos meses en el paro, entonces estaba en casa con ella y todo iba mejor. Ella estaba mejor, más tranquila. Entonces él ha empezado a trabajar con el camión y no puede estar en casa. También llega tarde, todavía más tarde que yo.

Pregunta: ¿Con quién está la niña?

Respuesta: A veces con la abuela y a veces está sola. Creo que también le va bien estar sola, ya es mayor. Ella llega a las 3 y se encuentra la comida. Come y está un poco en casa. Creo que mira poco la tele, se pone rápido con el ordenador y a chatear. Siempre está chateando. A las 5 o las 6 sale de casa y se va con sus amigas, no sé dónde. En el parque, para aquí, para allá. Nosotros no podemos estar siempre encima de ella, creo que ya es mayor para saber lo que le interesa.

Pregunta: ¿Hace alguna actividad extraescolar?

Respuesta: Ahora no. Cuando era más pequeña sí hacía, pero ahora no. Ella no quiere, pero también son muy caras. Hacer música, inglés... cuesta mucho dinero y nuestra situación es más bien justa.»

(Entrevistada 1. Entrevista realizada el 12-01-2012).

Cristina explica la situación social y económica de su familia y la relación con su hija. Los padres tienen una situación laboral inestable, van trabajando con periodos de desempleo. La madre tiene una relación difícil con su hija, dice que «cada día está más rebelde». En el instituto también tiene problemas y sus notas son bajas. La psicopedagoga le recomienda que debería estar más tiempo con su hija. Debería ayudarla a hacer los deberes y compartir más tiempo juntas. La madre trabaja en una tienda y llega a casa pasadas las 20 horas. El padre ha estado un tiempo desempleado y entonces estaba más tiempo en casa con su hija. La madre dice que entonces estaba más tranquila, «estaba mejor»; cuando el padre ha empezado a trabajar, su hija ha empeorado.

La madre explica que su hija termina las clases en el instituto a las 15 horas y muchas tardes está sola. Su abuela algunas veces puede estar con ella pero muchas tardes no hay ningún adulto y decide libremente qué hacer. La madre dice que le gusta mucho chatear y estar con las amigas, sin dar más detalles concretos. También resulta interesante el comentario sobre la edad de la niña, afirmando que es mayor para conocer los límites y saber qué es lo más adecuado. En referencia a las actividades 
extraescolares, la madre explica que actualmente no hace ninguna. Considera que son caras y su situación monetaria precaria no les permite hacer estos gastos.

Elena, maestra y madre de dos niñas de 16 y 13 años, de Tarragona, explica las actividades de sus hijas fuera del horario escolar:

«Mis hijas van a un instituto público de Tarragona y van solas, ya son mayores, no hay ningún problema. Como todas las niñas de su edad. Van solas y vuelven solas. Después en casa se encuentran la comida y comen. ¡No hay ningún problema!

Pregunta: ¿Cómo les va el instituto?

Respuesta: A la grande bien, a la pequeña le cuesta más. Tiene dislexia, tiene problemas de comprensión de las palabras y le cuesta todo bastante. La grande bien, hace bachillerato y va bien. ¡Estoy contenta!

Pregunta: ¿Qué hacen las niñas por las tardes, después del instituto?

Respuesta: Depende del día. Siempre hacen alguna cosa, también algún día tienen libre la tarde, para estudiar y así. Nosotros no tenemos abuelas para ayudarnos, viven lejos y no podemos contar con ellas, por esto pasan mucho tiempo solas. Un día van a piscina, una hora o así. Otro día hacen inglés y otro hacen teatro, les gusta mucho y dicen que se relajan mucho. Dicen que se encuentran muy bien con los otros compañeros. Siempre me dicen que les gusta mucho el teatro. Preparan una obra y la representan y van de aquí para allí. Está muy bien. Los otros días tienen libre, para salir con sus amigas y estudiar. Bueno, estudiar tienen que estudiar cada día un ratito.

Pregunta: ¿A qué hora llegan ustedes a casa?

Respuesta: Yo llego cada día a eso de las 18 horas o así, más o menos. Tengo un trabajo que me lo permite. Antes cuando las niñas eran más pequeñas contrataba una canguro para estar con ellas, para ayudarles con los deberes y que no estuviesen solas. Mi marido tiene una profesión más liberal, algunos días está toda la tarde en casa y algunos días llega muy tarde.» (Entrevistada 2. Entrevista realizada el 18-01-2012).

La entrevistada hace una descripción de la situación familiar. Se centra principalmente en las actividades extraescolares de sus hijas. Salen del instituto a las 15 horas y por la tarde realizan diferentes actividades: inglés, natación y teatro. Los otros días tienen libre para salir con las amigas. Las adolescentes tienen bien organizado el tiempo y saben que su madre llega a casa a las 18 horas, después del trabajo. Su padre algunas tardes también está en casa, otras llega muy tarde. La madre hace referencia al pasado, cuando las niñas eran más pequeñas, entonces tenían una canguro que les ayudaba con los deberes y siempre tenían compañía y apoyo adulto. Elena no señala conflictos de convivencia con sus hijas, no lo expresa, parece que tiene buena relación con ellas. También afirma que sus hijas van bien en el instituto. No destaca problemas con los profesores del instituto.

Teresa, de Lleida, trabaja en la empresa familiar y es madre de un niño de 14 años, explica concretamente la motivación principal para decidirse por un determinado centro educativo:

«Nosotros vivimos en un pequeño pueblo cerca de Lleida ciudad. Muy cerca. Mi hijo estudió en una escuela rural, eran en clase 16 alumnos y muy bien. Estábamos muy contentos en aquella escuela. Entonces tuvimos que decidir el instituto. Estuvimos todo $6^{\circ}$ de primaria pensado, los pros y los contras, las ventajas y los inconvenientes y al final decidimos llevarlo a una privada concertada. Ahora nosotros no vivimos en el pueblo, estamos en la ciudad. Pensamos que lo mejor para él era estudiar ESO en una privada sobre todo por el horario. Yo no veía nada claro que los dejaran salir a las 3 de la tarde.

Pregunta: ¿Por qué?

Respuesta: Nosotros antes estudiábamos hasta las 5 de la tarde y no pasaba nada. Ahora a las 3 ya les dejan y yo y mi marido no lo veíamos nada claro. Pensamos: ¿qué hará a partir de las 3 ?, nosotros no podemos estar siempre con él. Nuestra abuela es mayor y no podemos pedirle que siempre esté todas las tardes. Entonces pensamos: lo llevamos a la escuela privada, que los tienen hasta las 5 de la tarde, y nos olvidamos de los problemas.»

(Entrevistada 3. Entrevista realizada el 10-02-12).

La informante explica sus reflexiones, dudas e interrogantes sobre el centro educativo más adecuado para su hijo. Estuvieron reflexionando durante el último curso de primaria, proyectando las ventajas e inconvenientes. Al final decidieron que el horario era un tema importante. Sabían que los centros públicos terminan las clases a las 15 horas y en muchas ocasiones no hay una oferta clara, accesible, 
completa y de calidad de actividades extraescolares y menos en los pueblos. Pensaron que la mejor opción para evitar posibles problemas era un centro privado concertado. Las clases terminan a las 17 horas y también ellos mismos organizan actividades extraescolares. Para Teresa, el horario fue un tema central para decidirse por un centro educativo privado concertado.

Continuando con las aportaciones de los profesores, tienen una determinada mirada y reflexión sobre las actividades lectivas y no lectivas. El grupo de discusión de profesores de un equipo directivo de un centro de secundaria de Tarragona explica diferentes situaciones de su instituto:

\begin{abstract}
«Marina: Hay niños que están siempre en la calle. Nadie está con ellos. Los padres no sé qué hacen, pero están poco con ellos. Estos niños cuando salen del instituto están solos, sin ningún adulto. Toda la tarde solos, por la calle. ¡Imagínate!

Regina: Muchos ya fuman porros y todo esto. Toda la tarde solos en casa y después en la calle. Hacen lo que les da la gana, sin ningún control. Estos niños siempre están en la calle. Imagínate, a veces los ves en invierno a eso de las 11 o las 12 de la noche. Un martes o miércoles. Entonces me pregunto: ¿qué hacen a estas horas?, seguro que nada bueno.

Joaquín: Yo lo que sé es que para estos alumnos y para muchos el único espacio normalizado es el instituto. Para muchos fuera, en la calle, es un descontrol.»

(Entrevistada 4. Grupo de discusión 12-12-2011).
\end{abstract}

Estos profesores reflexionan sobre situaciones concretas de alumnos conocidos del instituto. Marina dice que algunos niños «siempre están en la calle» por la tarde. No tienen una figura adulta clara de referencia. Los docentes desconocen exactamente qué hacen sus padres. Regina afirma que a veces ha visto a los alumnos por la noche, muy tarde, «en invierno, a las 11 o 12 de la noche, un martes o miércoles». Joaquín concluye afirmando que para muchos alumnos el instituto es su único espacio normalizado. Tienen figuras (los profesores) adultas de referencia que establecen normas y reglas claras. Saben qué deben hacer para no tener problemas dentro de la institución y muchos se adaptan al instituto. Por el contrario, fuera del ámbito educativo, con sus familias y en la calle no tienen una referencia adulta clara. Sus padres no pasan un tiempo de calidad suficiente con ellos.

Irene, profesora psicopedagoga de un instituto de Barcelona, explica algunas situaciones de su centro educativo. Considera que hechos parecidos suceden también en otros centros educativos:

«Cada vez más nos encontramos con alumnos difíciles. Muchos pueden llegar a ser violentos. Nos piden continuamente que les pongamos límites, siempre. Valoran la disciplina y las normas. Al principio me extrañaba, pero después lo entendí.

Pregunta: ¿Lo puedes explicar un poco más?

Respuesta: Muchos niños están siempre solos. Sus padres no están o aparecen y desaparecen. Entonces estos niños pasan por muchos adultos. Muchos no tienen los referentes claros. Nosotros aquí en el instituto ponemos unas normas claras. Ellos saben lo que pueden hacer y lo que no. La verdad es que al principio les cuesta, pero con el tiempo lo valoran. ¡Fíjate! Muchos, cuando ya no están en el instituto, te los encuentras por la calle y te saludan. Muchos te paran, te presentan a su novia y te explican su vida. Te explican de qué trabajan. Se ven muy agradecidos con los profesores. En cambio, los «buenos» cuando te los encuentras por la calle ni te miran. Como si fueses invisible.

Pregunta: ¿Por qué piensas que pasa?

Respuesta: Muchos piensan que los niños y jóvenes son tontos y no lo son. Ellos ven las cosas. Muchos ven en la escuela una normalidad, un respeto, unas normas más o menos lógicas... Muchos en su casa no las encuentran. Muchos están solos toda la tarde, sin nadie adulto con ellos.»

(Entrevistada 5. Entrevista realizada el 19-11-2011).

La profesora explica su experiencia con determinados alumnos del instituto. Empieza comentando que cada vez llegan al centro adolescentes más difíciles, sin concretar. Hace referencia a situaciones familiares, sociales y económicas complejas que influyen en el desarrollo del infante. A continuación detalla que los alumnos «malos» son después los más agradecidos con los docentes. La profesora afirma que los adolescentes buscan y quieren unas normas claras. Al principio les cuesta, muchos no están acostumbrados, no es su normalidad en casa, pero progresivamente van integrando y aceptando la autoridad. Irene concluye su exposición afirmando que muchos adolescentes están solos por la 
tarde. Se socializan, crecen y construyen su identidad de forma caótica y fragmentaria principalmente interaccionando con el grupo de iguales.

Josep María, profesor de secundaria de Girona, explica la necesidad de introducir en los centros de secundaria la jornada intensiva:

«Creo que la jornada intensiva en los institutos es positiva para mejorar la educación. Te pondré unos ejemplos que se me ocurren a bote pronto. Todos los profesores sabemos que los alumnos están más receptivos y atentos por la mañana. Siempre son mejores las primeras horas, progresivamente los alumnos, también los profesores, vamos perdiendo fuerzas y capacidad de atención y concentración. Todos los profesores preferimos siempre las primeras horas, después las clases se hacen más difíciles y complicadas. Por ejemplo, situaciones difíciles no hay en las primeras horas, siempre son en las últimas. Antes, cuando hacíamos clase por las tardes, siempre era todo más difícil. Aquello era una guardería. Muchas tardes no hacíamos nada. Solamente pasar las horas y nada más.

Pregunta: ¿La jornada intensiva interesa a los profesores?

Respuesta: Creo que es lo mejor para los alumnos. Ellos hacen las mismas horas, ni más ni menos, y la distribución es más coherente. Más europea. En los países más desarrollados tienen el horario más compactado. Por la mañana, cuando los niños están más frescos, clase; y por la tarde actividades extraescolares, más lúdicas, estudiar y estar con la familia.

Pregunta: Pero actualmente no hay una red de actividades extraescolares extensa y de calidad para todos, y también hay muchas familias no pueden estar con sus hijos...

Respuesta: Creo que hay mucho trabajo por hacer. Las administraciones deberían crear actividades para todos y también las familias deberían ponerse las pilas. Creo que este horario es bueno para todos. Creo que toda la sociedad debería racionalizar más los horarios.»

(Entrevistado 6. Entrevista realizada el 14-01-2012).

El entrevistado justifica la implementación de la jornada intensiva en los institutos de secundaria. Afirma que los jóvenes, también los adultos, están más receptivos y atentos por la mañana. Los profesores prefieren hacer clase en las primeras horas, son más eficaces y hay menos conflictos. También la jornada intensiva racionaliza los horarios de los alumnos y toda la sociedad, en todas las profesiones posibles deberían introducirlos. Por la tarde, después del horario escolar, los alumnos deberían realizar actividades más lúdicas y creativas. Las diferentes administraciones deberían implementar actividades extraescolares de calidad para todos los niños. En la actualidad esto no sucede y la mayoría de las actividades no lectivas tienen un coste elevado para muchas familias.

Seguidamente se presenta la mirada de los alumnos. Resulta pertinente e interesante conocer sus opiniones y valoraciones sobre el tema abordado. El grupo triangular de alumnas de un instituto de Lleida dialoga sobre diferentes temas socioeducativos:

\footnotetext{
«Rosa: Todos quieren que seamos muy responsables, que lo tengamos todo claro, pero creo que lo hacen muy mal. Los jóvenes de hoy van muy subidos y se crecen con cualquiera. Nadie los puede parar. Muchos insultan, amenazan... a quien sea. En la ESO a veces insultan a los profesores y no pasa nada. Algunos les dicen imbécil, burro... Todo esto lo he visto yo.

Indira: Los niños que ahora tienen 12 años van muy subidos y nadie les para los pies.

Pregunta: ¿Los padres os orientan, son unos referentes para vosotras?

Indira: Para mí no, nunca me han dicho nada. Siempre me han dicho, ¿qué quieres hacer?, ¿quieres hacer FP o bachillerato? Me dejaron escoger a mí misma. Ahora me preguntan: ¿qué harás cuando termines el bachillerato?

Pregunta: ¿Qué hacéis después del instituto?

Indira: Nosotras estamos en casa y salimos por ahí. Somos mayores pero esto lo hacemos hace años ya. Cuando hay exámenes quedamos para estudiar.

Pregunta: ¿Y vuestros padres?

Indira: Ellos trabajan. Llegan cuando llegan. Muchas veces nuestra relación con nuestros padres es nula.»

(Entrevistada 7. Grupo triangular, 12-10-2011).
}

Las tres jóvenes estudian en un instituto de Lleida y cursan $1^{\circ}$ y $2^{\circ}$ de Bachillerato y $1^{\circ}$ de Grado Superior de Formación Profesional. Resulta interesante conocer sus opiniones sobre su familia y la forma de tomar determinadas decisiones vitales para ellas. También recuerdan etapas anteriores sin concretar, que podemos situar en la ESO. Rosa empieza reflexionando sobre el ideal de los padres 
hacia los adolescentes. Los adolescentes «están muy subidos» y no se relacionan correctamente con los adultos: padres y profesores. Manifiesta que no tienen límites. Indira afirma que habla poco con sus padres y no recibe una orientación y asesoramiento adecuados. También explica, sin entrar en detalles, las actividades que realiza fuera del horario lectivo, principalmente «estar en casa y salir por ahí». No menciona ninguna actividad de ocio significativa, solamente estar con las amigas y estudiar con las amigas. La informante manifiesta que sus padres principalmente trabajan y «llegan cuando llegan»y su relación con ellos es nula.

Erika, estudiante de $3^{\circ}$ de ESO en un centro público de Barcelona, reflexiona sobre la educación:

\begin{abstract}
«Yo estoy contenta con la educación recibida. Hago muchas cosas. Por las mañanas estoy en el instituto y por las tardes siempre hago algo. No todos los días, pero siempre tengo algo organizado. Hace muchos años que lo hago y lo hago porque me gusta pero también porque mis padres me apoyan.

Pregunta: ¿Puedes explicar las actividades que haces?

Respuesta: Hago música, voy al conservatorio tres días a la semana una hora y media. Cuando empiezas de pequeña solamente es un día pero cuando vas siendo mayor cada año son más días y más horas si quieres progresar. Entonces te obligan a escoger, ¿haces esto o aquello? Yo poco a poco me he ido definiendo por la música, me gusta mucho y me gustan las amigas que tengo allí. Nos entendemos bien, son como yo. También voy un día a teatro y cuando puedo me gusta ir a natación. En mi tiempo libre hago estas cosas y la verdad que no me queda mucho tiempo para otras. También cuando puedo quedo con mis amigas, ipero no siempre!

Pregunta: ¿Con todas estas cosas, tienes tiempo para estudiar?

Respuesta: Pues claro que sí. Me va muy bien en el instituto y saco buenas notas. No me quejo ni mis padres tampoco. Estudio siempre que puedo, antes o después de las actividades. También el fin de semana. La verdad es que lo llevo todo bastante al día.

Pregunta: ¿'Te gustaría dejar alguna actividad?

Respuesta: No, todas me gustan. Me relajan y conozco gente que si no, no conocería. Me gustan.»

(Entrevistada 8. Entrevista realizada el 16-01-2012).
\end{abstract}

Las aportaciones de la entrevistada resultan pertinentes e interesantes para comprender su valoración sobre las actividades extraescolares. Está contenta con la educación recibida, en general, se entiende en referencia a las relaciones con los profesores y compañeros de clase; también tiene buenos resultados académicos y una relación adecuada con sus padres. Todos los días tiene alguna actividad no lectiva planificada y explica que le gusta realizarlas; complementan sus conocimientos y conoce gente diferente. También expresa que se siente apoyada por sus padres. Se podría pensar que realizar tantas actividades tendría consecuencias negativas en los resultados académicos, aunque en su caso no es así. Tiene menos tiempo para estudiar y estar con las amigas, en consecuencia ha aprendido a aprovecharlo mejor; dice: «estudio siempre que puedo, antes o después de las actividades. También el fin de semana». No quiere dejar ninguna actividad, todas le aportan aspectos valiosos e interesantes. Todas le gustan y le relajan y puede conocer a gente diferente.

González (2016) afirma que las actividades no lectivas han sido identificadas como un elemento de impacto para el desarrollo cognitivo y social de los niños y adolescentes, especialmente con aquellos de entornos más desfavorecidos; ayuda a prevenir y compensar bajos resultados académicos. Resulta preocupante la implantación de la jornada intensiva en los institutos públicos para determinados alumnos. Muchos tienen todas las tardes libres, sin ninguna actividad planificada y sin control y supervisión de un adulto de referencia. Se requiere la implementación de una red extensa de actividades no lectivas de calidad y accesible para todos. En la actualidad, según Elzo (2000), los jóvenes se socializan de forma precaria y fragmentaria:

«Los jóvenes construyen su vida como si de un puzle se tratara, en efecto, con todo tipo de fichas, pero, y esto es capital, a diferencia de lo que sucede con los puzles en cuya tapa está el modelo a construir, muchos adolescentes no tienen modelo. Hacen el puzle sin tapa. Tienen las fichas, muchas fichas, pero construyen el puzle en gran medida a ciegas, tanteando, experimentando, quitando y poniendo piezas. Muy pocos lo terminan.» (p. 145). 


\section{Conclusiones}

La jornada intensiva está ampliamente instalada en los centros educativos públicos de secundaria de Cataluña. Los alumnos salen del centro a las 15 horas y tienen toda la tarde libre para realizar actividades más lúdicas y creativas. Muchos infantes y adolescentes no realizan ninguna actividad no lectiva. Carmona, Sánchez y Bekieva (2011), Alonso y Manassero (2007), Moriana, Alós, Alcalá, Pino, Herruzo y Ruiz (2006) y Moreno (2006) han realizado estudios relacionando las actividades extraescolares de calidad con mejores resultados académicos. Molina (2010) considera que la igualdad de oportunidades para todos los infantes no existe cuando se establece un horario lectivo continuo en los centros públicos de secundaria y no se facilita para todos actividades extraescolares por la tarde. Torrubia y Batlle (2002) destacan la relevancia de estas actividades para la formación y la constitución de la identidad social del menor. González (2016) afirma que los programas de ocio educativo propician impactos directos en los procesos de aprendizaje de los alumnos. Participar en determinadas actividades extraescolares equivale a dos meses sobre el progreso académico medio de los alumnos en un curso.

Se ha mostrado una relación entre titulaciones académicas de las madres y el ocio de sus hijos. Solamente el 30,0\% de los hijos de madres con titulaciones universitarias realizan ocio sedentario, mientras que lo hacen el 44,6\% de los hijos de las que tienen estudios de secundaria y el 46,8\% de aquellas sin estudios o con estudios mínimos. Consiste principalmente en estar en casa y mirar la televisión o navegar por internet. También se muestra la relación entre la profesión de los padres (grupos de clase social) y la participación en actividades extraescolares (deportivas y no deportivas). En el grupo de los padres con mejores condiciones laborales (grupo I), el 83,5 \% de los hijos participa en actividades deportivas y el 57,1 \% en no deportivas. En el grupo V, integrado exclusivamente por trabajadores manuales no cualificados, el $50 \%$ de los hijos no participa en actividades deportivas y aproximadamente el $80 \%$ no participa en actividades no deportivas. Se establece una relación entre el nivel adquisitivo de las familias y las actividades realizadas por sus hijos. Faltaría analizar y profundizar en la calidad de las actividades no lectivas propuestas en futuras investigaciones.

Concretando aportaciones relevantes de las entrevistadas, Irene, psicopedagoga de un instituto de Barcelona, explica que cada día tienen en el instituto más casos difíciles, «muchos niños están siempre solos. Sus padres no están o aparecen y desaparecen». Muchos no tienen referentes claros adultos, llegan a casa y no hay nadie. Durante toda la tarde están solos y deciden libremente cómo pasar el tiempo. Cristina, madre de una adolescente de 13 años, explica la compleja relación con su hija: «me pone histérica». Mientras su marido estuvo parado y en casa, su hija estaba más tranquila; en cambio, cuando se reincorporó al trabajo la situación empeoró de nuevo. La niña no realiza ninguna actividad extraescolar, por la tarde está en casa y después con las amigas en el parque. La motivación principal para no realizar ninguna actividad es económica, considera que tienen un coste excesivo. En cambio, Teresa considera que los centros de secundaria públicos no son la mejor opción para su hijo, en consecuencia lo matriculó en un centro privado concertado, fundamentalmente por el horario (mañana-tarde), «así se olvidan de problemas».

El ideal educativo de fomentar la igualdad de oportunidades para todos los alumnos queda truncado con la implantación de la jornada intensiva sin facilitar el acceso a actividades extraescolares. Consideramos que si se mantiene el horario continuo en los centros educativos las administraciones deberían implementar una sólida y estable red de actividades por las tardes para todos los alumnos; en el caso de no desarrollarse, sería mejor reintroducir el horario partido (mañana-tarde) para equilibrar, orientar y mejorar las condiciones académicas, sociales y familiares de todos los alumnos.

\section{Referencias}

Ander Egg, E. (2000). Métodos y técnicas de investigación social. Buenos Aires: Lumen-Humanitas.

Alonso, A., \& Manassero, M. (2007). Las actividades extraescolares relacionadas con la ciencia y la tecnología. Revista Electrónica de Investigación Educativa. 9(1). Recuperado el 05 de julio de 2019, de http://redie.uabc.mx/redie/article/view/156.

Bauman, Z. (2003). Modernidad líquida. México, D. F.: Fondo de Cultura Económica.

Caivano, F. (2012, 6 de mayo). La jornada intensiva divide a padres y docentes de la ESO. El Periódico. 
Carmona, C., Sánchez, P., \& Bekieva, M. (2011). Actividades extraescolares y rendimiento académico. Diferencias en autoconcepto y género. Revista de Investigación Educativa. 29(2), pp. 447-466. Recuperado el 05 de julio de 2019, de http://revistas.um.es/rie/article/view/111341.

Departament de Salut (2016). Enquesta de salut de Catalunya 2015. Barcelona: Direcció General de Planificació en Salut. Recuperado de http://salutweb.gencat.cat/web/.content/home/el_departament/estadistiques__ sanitaries/enquestes/esca_2015.pdf.

Departament de Salut (2013). Enquesta de salut de Catalunya 2012. Barcelona: Direcció General de Planificació en Salut. Recuperado de http://salutweb.gencat.cat/web/.content/home/el_departament/estadistiques_s sanitaries/enquestes/02_enquesta_catalunya_continua/documents/arxius/informeesca2012.pdf.

Elzo, J. (2000). El silencio de los adolescentes: lo que no cuentan a sus padres. Madrid: Temas de hoy.

Elzo, J. (2008). La voz de los adolescentes. Madrid: PPC.

Feito, R. (2007). Tiempos escolares. El debate sobre la jornada escolar continua y partida. Cuadernos de Pedagogía, 365, pp. 74-79.

Fernández Enguita, M., Mena, L., \& Rivière, J. (2010). Fracaso y abandono escolar en España. Barcelona: Fundación La Caixa. Recuperado el 5 de julio de 2019, de https://www.forotf.com/u/uploads/File/CAPWIN/La\%20caixa.pdf.

Fernández Enguita, M. (2015). La ciencia que sustenta la jornada continua. En su web. Recuperado el 5 de julio de 2019, de https://blog.enguita.info/2017/03/la-ciencia-que-sustenta-la-jornada_19.html.

González, S. (2016). Quin impacte tenen les activitats extraescolars sobre els aprenentatges dels infants i joves? Barcelona: Fundació Jaume Bofill. Recuperado el 5 de julio de 2019, de http://www.fbofill.cat/sites/default/files/activitatsesxtraescolars_Que_funciona_04_191016.pdf.

Ibáñez, M. (2016, 15 de enero). Ensenyament amplía el plan para probar el horario intensivo en primaria. El Periódico.

Molina, F. (2010). Educación inclusiva y convivencia intercultural: presente y futuro. Revista de la Asociación de Sociología de la Educación (RASE), 3(1), pp. 41-53. Recuperado de https://ojs.uv.es/index.php/RASE/article/view/8626.

Morales, F. J. (2013). La organización de la jornada escolar. Reflexiones sobre el estado de cuestión para un debate necesario. Revista Edetania, 44, pp. 111-133. Recuperado el 5 de julio de 2019, de file:///C:/Users/User/Downloads/Dialnet-LaOrganizacionDeLaJornadaEscolar-4596203.pdf.

Morales, F. J. (2015). El cambio de jornada escolar en los centros educativos: evaluación de las razones que lo motivan y los efectos que provoca. Tesis doctoral, UNED, Madrid.

Morales, F. J., Galán, A., \& Pérez, R. (2017). Jornada escolar partida y continua. ¿Existen evidencias que motiven el cambio en la gestión del tiempo escolar en España? Revista Complutense de Educación. 28(3), pp. 965- 984. Recuperado de doi: https://doi.org/10.5209/RCED.55335.

Moreno, F. (2006). La importancia de las actividades extraescolares. La revista de la Consejería de Educación de la Embajada de España en Andorra. 2. 56-60. Recuperado el 5 de julio de 2019, de https://sede.educacion.gob.es/publiventa/pirineos-n-2-revista-de-la-consejeria-de-educacionde-la-embajada-de-espana-en-andorra/ensenanza-lengua-espanola/13105.

Moriana, J., Alós, F., Alcalá, R., Pino, M. J., Herruzo, J., \& Ruiz, R. (2006). Actividades extraescolares y rendimiento académico en alumnos de educación secundaria. Electronic journal of research in educational psychology, 4(8), pp. 35-47. Recuperado el 5 de julio de 2019, de http://www.redalyc.org/articulo.oa?id=293123488002.

Sacristán, G. (2008). Ni padres ni maestros han de decidir sobre la jornada. Revista Escuela, 3786 (660). Recuperado el 5 de julio de 2019, de http://fapar.org/web/wp-content/uploads/2014/07/Gimeno_jornada.pdf.

Save the Children (2015). Iluminando el futuro. Invertir en educación es luchar contra la pobreza infantil. Madrid: Save the Children. Recuperado el 5 de julio de 2019, de https://www.savethechildren.es/sites/default/files/imce/docs/pobreza-equidad-educativa-espana_iluminando-el-futuro.pdf.

Síndic de Greuges de Catalunya (2014). Informe sobre el dret al lleure educatiu $i$ a les sortides i colònies escolars. Recuperado el 5 de julio de 2019, de http://www.sindic.cat/site/unitFiles/3687/Informe $\% 20$ sobre $\% 20$ el $\% 201$ leure $\% 20$ educatiu.pdf. 
Tahull, J. (2012). La modernidad y la postmodernidad. Anàlisi sociologica del concepte d'autoritat al sistema educatiu català. Tesis doctoral, Universitat de Lleida, Lleida.

Tahull, J. (2016). La compleja transición de los adolescentes hacia la vida adulta. Revista de Antropología Experimental, 16(3), pp. 27-44. doi: 10.17561/rae.v0i16.2853

Tahull, J., Molina, F., \& Montero, I. (2017). Malestar familiar. ¿Tiene incidencia la pobreza infantil y juvenil en los resultados académicos? Revista Análisis, 49(90), pp. 39-62. doi: 10.15332/s01208454.2017.0090.02

Tahull, J., \& Montero, I. (2019). Voces del franquismo. La oscuridad de la razón. Barcelona: Caligrama.

Terrén, E. (1999). Educación y modernidad: entre la utopía y la burocracia. A Coruña: Anthropos.

Tinajas, A. (2012). ¿Jornada escolar continua o jornada escolar partida? Revista Iberoamericana de Educación, 59(3), pp. 1-10. doi: 10.35362/rie5931382

Torrubia, R., \& Batlle, R. (2002). Eduquem més enllà de l'borari lectiu. Barcelona: FAPAC- Fundació Catalana de l'Esplai.

Vázquez, A., \& Manassero, M. (2007). Las actividades extraescolares relacionadas con la ciencia y la tecnología. Revista Electrónica de Investigación Educativa, 9(1). Recuperado el 5 de julio de 2019, de http://www.redalyc.org/pdf/155/15590103.pdf.

Vicens, L. (2018, 15 de diciembre). Jornada intensiva a l'escola, una prova en qüestió. Diario $A R A$. 